\title{
Suplementos Energéticos para Recria de Novilhas de Corte em Pastagens Anuais. Desempenho Animal ${ }^{1}$
}

\author{
Davi Teixeira dos Santos ${ }^{2}$, Marta Gomes da Rocha ${ }^{3}$, Fernando Luiz Ferreira de Quadros ${ }^{3}$, \\ Teresa Cristina Moraes Genro ${ }^{4}$, Denise Baptaglin Montagner ${ }^{5}$, Edna Nunes Gonçalves ${ }^{2}$, \\ Juliano Roman 6
}

\begin{abstract}
RESUMO - Foi avaliado o desempenho de novilhas de corte dos três aos doze meses de idade, mantidas em pastagem cultivada logo após o desmame (experimento 1) e no primeiro inverno pós-desmame (experimento 2), com ou sem o fornecimento de suplementos energéticos. No período de 16/02 a 21/04/2001, as novilhas permaneceram em pastagem de milheto, exclusivamente sob pastejo (PAST ), suplementadas com grão de milho moído $\left(\mathrm{PAST}_{1} / \mathrm{M}\right)$ ou com polpa cítrica peletizada e moída ( $\left.\mathrm{PAST}_{1} / \mathrm{P}\right)$. No período de $13 / 07$ a 09/10/2001, as novilhas foram mantidas em pastagem de aveia preta e azevém, sem suplementação ( PAST $_{2}$ ), suplementadas com grão de milho moído $\left(\mathrm{PAST}_{2} / \mathrm{M}\right)$ ou suplementadas com casca de soja $\left(\mathrm{PAST}_{2} / \mathrm{C}\right)$. Peso vivo (PV), ganho de peso diário médio (GDM) e escore de condição corporal (ECC) foram avaliados. No experimento 1, os animais suplementados apresentaram maior PV final, GDM e ECC que os não-suplementados, não diferindo entre si. No experimento 2, as novilhas suplementadas com casca de soja apresentaram maior GDM e PV final que as não-suplementadas, enquanto as suplementadas com grão de milho ficaram em posição intermediária. O maior ECC foi obtido pelos animais de $\mathrm{PAST}_{2} / \mathrm{C}$, seguidos de $\mathrm{PAST}_{2} / \mathrm{M}$ e, por último, de $\mathrm{PAST}_{2}$. Novilhas de corte desmamadas aos $60-$ 90 dias devem ser suplementadas no período inicial pós-desmama, para que atinjam desenvolvimento satisfatório nesta fase do crescimento. Os subprodutos polpa cítrica e casca de soja podem substituir o grão de milho como suplementos energéticos para recria de novilhas de corte.
\end{abstract}

Palavras-chave: casca de soja, gramíneas anuais, grão de milho, polpa cítrica, sistemas de recria

\section{Energy Supplements for Beef Heifers Rearing at Annual Pastures. Animal Performance}

ABSTRACT - It was evaluated beef heifers performance from three until twelve months of age, when they were reared in cultivated pasture soon after their weaning (experiment 1) and in the first winter post-weaning (experiment 2), with or without the supply of energy

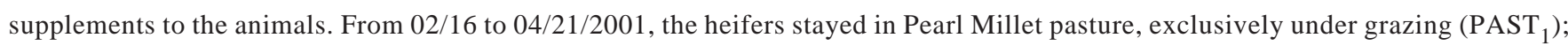
supplemented with milled corn grain $\left(\mathrm{PAST}_{1} / \mathrm{C}\right)$ or supplemented with pellet citric pulp (PAST 1 /P). From 07/13 to 10/09/2001, the heifers were maintained in oat plus italian ryegrass pasture without supplementation to the animals ( $\mathrm{PAST}_{2}$ ); supplemented with milled corn grain $\left(\mathrm{PAST}_{2} / \mathrm{C}\right)$ or supplemented with soy hull $\left(\mathrm{PAST}_{2} / \mathrm{H}\right)$. The evaluated variables of animal performance were live weight $(\mathrm{LW})$, average daily gain (ADG) and body condition score (BCS). In the experiment 1, supplemented animals presented larger values of final LW, ADG and BCS in relation to the non supplemented, ones the supplemented treatments not differing to each other. In experiment 2, the soy hull supplemented heifers showed greater ADG and final LW than non supplemented heifers, with the corn grain supplemented group in an intermediary position. The highest BCS was obtained by the animals of $\mathrm{PAST}_{2} / \mathrm{H}$, followed by $\mathrm{PAST}_{2} / \mathrm{C}$ and, at last, of $\mathrm{PAST}_{2}$. Beef heifers weaned at 60-90 days should be supplemented in the initial post-weaning period, enabling them to reach satisfactory development in this phase of growth. The by-products citric pulp and soy hull can substitute the corn grain as energy supplements for rearing of beef heifers.

Key Words: soy hull, annual grasses, corn grain, citric pulp, rearing systems

\section{Introdução}

A produção de gado de corte no Brasil apresenta, historicamente, baixos índices reprodutivos, que afetam a eficiência do sistema produtivo em geral.
A elevada idade das novilhas ao primeiro acasalamento, normalmente entre 36 e 48 meses, bem como as baixas taxas de repetição de prenhez das vacas, estão diretamente relacionadas à inexistência de planejamento alimentar para fêmeas

\footnotetext{
${ }_{1}^{1}$ Parte da dissertação de mestrado do primeiro autor, PPGZ-UFSM, Santa Maria, RS.

2 Zootecnista, aluno do PPGZ-UFSM, Santa Maria, RS, Bolsista CAPES (daviteixeira@hotmail.com).

${ }^{3}$ Engenheira-Agrônoma, Dra., Professora Adjunto do Departamento de Zootecnia, UFSM, Santa Maria, RS (tata@via-rs.net). Bolsista CNPq.

4 Zootecnista, Dra ., Pesquisadora EMBRAPA Pecuária Sul, Bagé, RS (cristina@ccpsul.embrapa.br).

5 Zootecnista, aluno do PPGZ-UFSM, Santa Maria, RS, Bolsista CNPq (setorforrageiras@bol.com.br).

${ }^{6}$ Aluno do curso de Graduação em Medicina Veterinária, UFSM (mochovet@yahoo.com.br).
} 
em recria e a ineficiência do sistema de manejo dos ventres no pós-parto.

No Rio Grande do Sul, com a pastagem nativa constituindo a base da alimentação do rebanho, a baixa produção de forragem durante o inverno compromete o desempenho reprodutivo subsequiente das vacas. As categorias que mais sofrem com a redução no suprimento de nutrientes são os bovinos em fase de crescimento, pelas maiores exigências nutricionais, e vacas paridas, pela maior demanda de nutrientes para a produção de leite (Lana \& Gomes Jr., 2002). Técnicas como o desmame aos 60-90 dias têm apresentado resultados expressivos quanto à recomposição do estado corporal das vacas e aumentos na taxa de repetição de prenhez. Com relação aos bezerros desmamados precocemente, deve existir entre os produtores a preocupação de que machos e fêmeas atinjam o peso-alvo preconizado, respectivamente, para abate e primeiro acasalamento. $\mathrm{Na}$ maioria das vezes, no entanto, apenas os machos são contemplados com alimentação diferenciada durante a recria, em detrimento do desenvolvimento necessário às novilhas de mesma idade. $\mathrm{O}$ estudo e a aplicação de sistemas viáveis integrados de alimentação e manejo na recria de fêmeas, visando a redução na idade de acasalamento, são fundamentais para o desenvolvimento da pecuária de corte, em condições brasileiras.

Em sistemas intensivos de produção, a dependência do uso exclusivo de pastagens aumenta os riscos de fracasso, principalmente no que se refere ao acasalamento das fêmeas com 14 ou 18 meses de idade. Para esta categoria, é indispensável elevado nível alimentar, que pode ser oportunizado com o fornecimento de suplementos concentrados. A suplementação energética em pastagens de alta qualidade constitui uma alternativa para aumentar a velocidade de crescimento dos animais, a partir de melhor balanceamento dos nutrientes da dieta e de aumento no consumo total de matéria seca (MS).

Entre as espécies forrageiras utilizadas no Rio Grande do Sul para incrementar quali e quantitativamente a dieta dos animais, destacam-se o milheto (Pennisetum americanum (L.) Leeke), na estação estival, e a mistura de aveia preta (Avena strigosa Schreb) e azevém (Lolium multiflorum Lam), no período hiberno-primaveril. Considerando-se que são gramíneas anuais e sua implantação nas propriedades rurais normalmente ocorre na mesma área, em épocas distintas, haverá um período de escassez alimentar entre a utilização da pastagem de verão e a de inverno. Neste período, comumente chamado 'vazio de outono', animais mantidos em pastagem nativa podem perder, em média, $0,2 \mathrm{~kg} / \mathrm{dia}$ (Moojen, 1991). Pesquisadores têm apresentado alternativas de alimentação para esta época, basicamente com fornecimento de forragem conservada e/ou rações concentradas aos animais.

O potencial de ganho de peso de novilhas durante o período de utilização das pastagens de verão e de inverno foi otimizado com o fornecimento de suplementos energéticos, para estudar a possibilidade de explorar um crescimento compensatório dos animais no período hiberno-primaveril.

\section{Material e Métodos}

Os experimentos foram desenvolvidos em área do Departamento de Zootecnia da Universidade Federal de Santa Maria, RS, localizada na Depressão Central do estado, com altitude de $95 \mathrm{~m}$, latitude $29^{\circ}$ $43^{\prime}$ sul e longitude $53^{\circ} 42^{\prime}$ oeste. O clima da região é Cfa (subtropical úmido), conforme classificação de Köppen (Moreno, 1961). A área experimental totaliza 5,8 ha com seis subdivisões de 0,7 ha (unidades experimentais), mais uma área de 1,6 ha para alojar animais reguladores da massa de forragem. Foram utilizadas novilhas mestiças, oriundas de cruzamentos entre as raças Charolês, Nelore, Hereford e Angus, com idade e peso médios iniciais de 100 dias e $95,5 \mathrm{~kg}$, respectivamente. Os animais foram agrupados em três lotes uniformes quanto ao tipo racial, sendo os lotes distribuídos ao acaso nos tratamentos em ambos os experimentos, descritos a seguir:

Experimento 1 - as novilhas desmamadas com idade entre 60 e 90 dias foram mantidas em pastagem de milheto dos três aos cinco meses de idade, sob pastejo contínuo com lotação variável, recebendo ou não suplementos energéticos. A pastagem foi implantada no dia 03/01/2001 pelo método convencional, utilizando-se $200 \mathrm{~kg} / \mathrm{ha}$ de adubo da fórmula 05-20-20 e $35 \mathrm{~kg} / \mathrm{ha}$ de sementes de milheto. A adubação de cobertura foi de $150 \mathrm{~kg} / \mathrm{ha}$ de nitrogênio (N), na forma de uréia, parcelada em duas aplicações. As novilhas iniciaram o período de pastejo em 16/02, distribuídas nos tratamentos: $\mathrm{PAST}_{1}$ - pastagem de $^{-}$ milheto, sem suplementação aos animais; $\mathrm{PAST}_{1} / \mathrm{M}$ pastagem de milheto + suplementação com grão de milho moído; $\mathrm{PAST}_{1} / \mathrm{P}$ - pastagem de milheto + suplementação com polpa cítrica peletizada e moída.

\section{R. Bras. Zootec., v.34, n.1, p.209-219, 2005}


O teor de proteína bruta (PB) dos suplementos utilizados nesta etapa foi analisado previamente ao experimento, sendo corrigido com uréia para $12 \%$ PB. Os suplementos foram fornecidos diariamente às $8 \mathrm{~h} 30$, em nível de $0,9 \%$ do peso vivo (PV) dos animais, com base na MS. A quantidade de suplemento oferecida foi regulada semanalmente conforme o ajuste da carga animal. Foram utilizadas quatro novilhas-teste por unidade experimental, adotando número variável de animais reguladores, visando conservar a massa de forragem (MF) entre 1.800 e $2.000 \mathrm{~kg} / \mathrm{ha}$ de MS e oferta de forragem de $10 \%$ do PV. Os animais foram pesados nos dias 16/02, 10/03, 30/03 e 21/04. As pesagens inicial e final foram precedidas de jejum de 12 horas. O manejo sanitário constou de duas aplicações de ivermectina, em 14/02 e 30/03.

Após o encerramento do experimento 1 e durante a fase de estabelecimento da pastagem de inverno, as novilhas foram mantidas em uma área de pastagem nativa invadida por capim-annoni (Eragrostis planna).

Experimento 2 - as novilhas permaneceram dos oito aos onze meses de idade em pastagem de aveia preta mais azevém, sob pastejo contínuo com lotação variável. A pastagem foi implantada pelo método de semeadura direta, em 11/05/2001, quando foram utilizados $300 \mathrm{~kg} / \mathrm{ha}$ de adubo da fórmula 05-20-20, $80 \mathrm{~kg} / \mathrm{ha}$ de sementes de aveia preta e $45 \mathrm{~kg} / \mathrm{ha}$ de sementes de azevém. Em cobertura, foram aplicados $150 \mathrm{~kg} / \mathrm{ha}$ de $\mathrm{N}$ na forma de uréia, parcelados em três aplicações. No dia 13/07, as novilhas ingressaram na pastagem com peso médio de $110 \mathrm{~kg}$, distribuídas nos tratamentos: $\mathrm{PAST}_{2}$ - pastagem de aveia preta e azevém, sem suplementação aos animais; $\mathrm{PAST}_{2} / \mathrm{M}$ pastagem de aveia preta e azevém + suplementação com grão de milho moído; $\mathrm{PAST}_{2} / \mathrm{C}$ - pastagem de aveia preta e azevém + suplementação com casca de soja. Os suplementos foram fornecidos diariamente às $14 \mathrm{~h}$, a $0,9 \%$ do PV dos animais, com base na MS. A quantidade de suplemento oferecida foi regulada semanalmente, conforme a carga animal, ajustada a uma oferta de forragem de $10 \%$ do PV. Foram utilizadas três novilhas-teste por unidade experimental, além de número variável de animais reguladores, para conservar a MF entre 1.300 e $1.500 \mathrm{~kg} / \mathrm{ha}$ de MS. As pesagens dos animais foram realizadas em 13/07, 11/08, 07/09 e 09/10, todas precedidas de jejum de seis horas. O manejo sanitário dos animais constou de duas aplicações (10/07 e 18/09) de ivermectina.

As demais metodologias aplicadas foram comuns aos dois experimentos, sendo as avaliações das pas- tagens e dos animais realizadas no início e final de cada período experimental: experimento $1=21$ dias $\mathrm{e}$ experimento $2=28$ dias. Para determinação da massa de forragem, foi utilizada a técnica da dupla amostragem, descrita por Gardner (1986). Os parâmetros qualitativos da forragem foram estimados a partir de amostras coletadas por dois avaliadores treinados, em cada unidade experimental, por intermédio da técnica de simulação do pastejo (Euclides et al., 1992). O conteúdo de PB da forragem e dos suplementos foi estimado pela determinação do $\mathrm{N}$ pelo método micro Kjedahl (AOAC, 1984). A digestibilidade in vitro da matéria orgânica (DIVMO) foi determinada com base na metodologia de Tilley \& Terry (1963). A partir dos resultados de DIVMO, estimou-se o conteúdo de energia metabolizável, pela fórmula: $\mathrm{EM}(\mathrm{Mcal} / \mathrm{kg})=$ DIVMO $\mathrm{x} \% \mathrm{MO} \mathrm{x}$ 3,652 (para forragem) ou 3,564 (para concentrados) (Maff, 1977).

Em todas as pesagens realizadas, as novilhas foram submetidas a uma avaliação subjetiva da condição corporal (ECC), conforme adaptação da metodologia proposta por Lowman et al. (1973), com escores de 1,0 (magro) a 5,0 (gordo), atribuídos por observação visual. O ganho de peso diário médio (GDM) dos animais, em cada período experimental, foi obtido pela diferença de peso entre as pesagens, dividido pelo número de dias do período. Para as estimativas de GDM necessários para o acasalamento aos 14,18 ou 24 meses, considerou-se peso de vaca adulta de $420 \mathrm{~kg}$ e $65 \%$ deste valor $(273 \mathrm{~kg})$ como peso alvo para o início do acasalamento.

$\mathrm{O}$ delineamento experimental foi o inteiramente casualizado com duas repetições, em um esquema fatorial $3 \times 3$ (três tratamentos e três períodos). Os dados foram submetidos à análise de variância, por intermédio do General Linear Models Procedure (Proc GLM). Quando detectadas diferenças entre as médias, aplicou-se o teste Tukey a 5\%. O modelo matemático geral referente à análise das variáveis estudadas é representado por:

$$
\mathrm{Y}_{\mathrm{ijk}}=\mu+\mathrm{T}_{\mathrm{i}}+\mathrm{R}_{\mathrm{k}}\left(\mathrm{T}_{\mathrm{i}}\right)+\mathrm{P}_{\mathrm{j}}+(\mathrm{TP})_{\mathrm{ij}}+\varepsilon_{\mathrm{ijk}}
$$

em que $Y_{\mathrm{ijk}}$ representa as variáveis dependentes; $\mu$, a média de todas as observações; $T_{i}$, o efeito do i-ésimo tratamento alimentar; $\mathrm{R}_{\mathrm{k}}\left(\mathrm{T}_{\mathrm{i}}\right)$, o efeito da k-ésima repetição dentro do i-ésimo tratamento (erro a); $\mathrm{P}_{\mathrm{j}}$, o efeito do j-ésimo período; $(\mathrm{TP})_{\mathrm{ij}}$, a interação entre o i-ésimo tratamento e o j-ésimo período; e $\varepsilon_{\mathrm{ijk}}$, o erro

R. Bras. Zootec., v.34, n.1, p.209-219, 2005 
experimental total (erro b). Para análise do desempenho seqüencial, ao longo do período total de avaliação, cada animal foi considerado uma repetição, excluindo do modelo o efeito de períodos $\left(\mathrm{P}_{\mathrm{j}}\right)$ e a interação entre tratamento e período $\left(\mathrm{TP}_{\mathrm{ij}}\right)$.

\section{Resultados e Discussão}

Os valores médios de massa e oferta de forragem na pastagem de milheto foram de 1901,4 kg/ha de MS e $10,3 \%$ do $\mathrm{PV}$, respectivamente, não existindo diferença $(\mathrm{P}>0,05)$ entre tratamentos e entre períodos para estas variáveis. O peso vivo médio (média de $95,5 \mathrm{~kg})$ dos animais não diferiu $(\mathrm{P}>0,05)$ entre os tratamentos, por ocasião do início do experimento 1 . O escore médio de condição corporal inicial, ajustado por covariância, foi de 2,55 (escala 1 a 5). Na Tabela 1 , são apresentados os resultados de GDM, PV e ECC das novilhas ao término de cada período, correspondentes à utilização da pastagem de milheto (16/02 a 21/04/2001).

As variações no GDM entre os períodos experimentais não serão discutidas neste experimento, uma vez que os animais não foram submetidos a jejum prévio nas pesagens intermediárias. É relevante, todavia, a comparação entre os tratamentos dentro de cada período, em que se observou diferente resposta da suplementação ao longo do ciclo de pastejo. Estes resultados podem ser explicados pelas mudanças ocorridas nas características estruturais da pastagem, representadas sobretudo pela alteração na relação lâmina foliar/colmo (F/C) (Tabela 2), que apresentou comportamento linear decrescente $(\mathrm{P}<0,05)$. As mudanças na estrutura da pastagem afetam o tamanho do bocado, e este, por sua vez, é positivamente relacionado com a MS representada pela porção de folhas e pela relação F/C das plantas (Poppi et al., 1987). No primeiro período de avaliação, quando a proporção de folhas verdes da pastagem esteve acima de $70 \%$ em todos os tratamentos, o fornecimento de suplementos não interferiu no desempenho individual dos animais. Com o avanço do ciclo do milheto e significativo decréscimo na relação $\mathrm{F} / \mathrm{C}$, provavelmente as novilhas não conseguiram obter exclusivamente da forragem um aporte satisfatório de nutrientes. As alterações estruturais da pastagem não afetaram $(\mathrm{P}>0,05)$ a qualidade da forragem aparentemente consumida pelos animais (Tabela 3), mas provavelmente a maior dispersão das lâminas foliares no estrato superior dificultou o pro-
Tabela 1- Médias de ganho de peso diário médio (GDM), peso vivo (PV) e escore de condição corporal (ECC) das novilhas, por tratamento e período (experimento 1)

Table 1 - Means of average daily gain (ADG), live weight (LW) and body condition score (BCS) of beef heifers, by treatment and period (experiment 1)

\begin{tabular}{|c|c|c|c|c|}
\hline \multirow{3}{*}{$\begin{array}{l}\text { Tratamento } \\
\text { Treatment }\end{array}$} & \multicolumn{3}{|c|}{$\begin{array}{c}\text { Período } \\
\text { Period }\end{array}$} & \multirow{3}{*}{$\begin{array}{c}\text { Média } \\
\text { Mean }\end{array}$} \\
\hline & $16 / 02 \mathrm{a}$ & $09 / 03 \mathrm{a}$ & $31 / 03 \mathrm{a}$ & \\
\hline & $08 / 03$ & $30 / 03$ & $21 / 04$ & \\
\hline \multicolumn{5}{|c|}{ GDM (kg/animal) } \\
\hline \multicolumn{5}{|c|}{$A D G($ kg/animal $)$} \\
\hline $\mathrm{PAST}_{1}$ & 0,655 & $0,696 b$ & $-0,223 b$ & $0,376 b$ \\
\hline $\operatorname{GRASS}_{1}$ & & & & \\
\hline $\mathrm{PAST}_{1} / \mathrm{M}$ & 0,667 & $1,024 \mathrm{a}$ & $0,141 \mathrm{a}$ & $0,611 \mathrm{a}$ \\
\hline $\begin{array}{l}G R A S S_{1} / C \\
\mathrm{PAST}\end{array}$ & & & & \\
\hline $\begin{array}{l}\text { PAS } 11 / \mathrm{P} \\
G R A S S, / P\end{array}$ & 0,619 & $1,101 \mathrm{a}$ & $0,125 \mathrm{a}$ & $0,615 \mathrm{a}$ \\
\hline \multicolumn{5}{|c|}{ PV (kg) } \\
\hline & & $L W(k g)$ & & \\
\hline $\mathrm{PAST}_{1}$ & 109,3 & $123,9 b$ & $119,2 \mathrm{~b}$ & 117,4 \\
\hline$G_{R A S S_{1}}$ & & & & \\
\hline $\mathrm{PAST}_{1} / \mathrm{M}$ & 109,5 & $131,0 \mathrm{a}$ & $134,0 \mathrm{a}$ & 124,8 \\
\hline $\operatorname{GRASS}_{1} / C$ & & & & \\
\hline $\mathrm{PAST}_{1} / \mathrm{P}$ & 108,5 & $131,6 \mathrm{a}$ & $134,2 \mathrm{a}$ & 124,7 \\
\hline \multicolumn{5}{|c|}{$\operatorname{ECC}(1-5)$} \\
\hline \multicolumn{5}{|c|}{$B C S(1-5)$} \\
\hline $\mathrm{PAST}_{1}$ & 2,70 & $2,74 \mathrm{~b}$ & $2,65 \mathrm{~b}$ & $2,70 \mathrm{~b}$ \\
\hline $\operatorname{GRASS}_{1}$ & & & & \\
\hline $\mathrm{PAST}_{1} / \mathrm{M}$ & 2,85 & $2,83 \mathrm{ab}$ & $2,85 \mathrm{a}$ & $2,84 \mathrm{a}$ \\
\hline $\begin{array}{l}{G R A S S_{1} / C} / C \\
\mathrm{PAST}_{1} / \mathrm{P}\end{array}$ & 2,83 & $2.98 \mathrm{a}$ & $290 \mathrm{a}$ & $2,90 \mathrm{a}$ \\
\hline GRASS $/ P$ & & $2,90 \mathrm{a}$ & $2,90 \mathrm{~d}$ & $2,90 \mathrm{~d}$ \\
\hline
\end{tabular}

cesso de apreensão do alimento, reduzindo o consumo e/ou aumentando a demanda energética para a condução desta pesquisa.

A baixa densidade de forragem e elevada dispersão espacial de folhas de pastagens tropicais podem dificultar o processo de ingestão pelos animais, em função do aumento no tempo necessário à formação do bocado (Carvalho et al., 2001). Possível aumento no tempo diário de pastejo raramente consegue compensar, em desempenho animal, a baixa disponibilidade de folhas verdes de pastagens em final de ciclo (Caton \& Dhuyvetter, 1997). Nesta situação, os animais não-suplementados foram os mais prejudicados e, com isso, o GDM médio de $\mathrm{PAST}_{1} / \mathrm{M} \mathrm{e} \mathrm{PAST}_{1} / \mathrm{P}(0,613 \mathrm{~kg})$, que não diferiram entre si $(\mathrm{P}>0,05)$, foi $63 \%$ superior $(\mathrm{P}<0,05)$ ao obtido em $\operatorname{PAST}_{1}(0,376 \mathrm{~kg})$.

Muehlmann et al. (1997) consideraraminsatisfatório o desempenho de bezerras desmamadas aos 90 dias 
Tabela 2 - Proporção lâmina foliar/colmo (\%) e relação lâmina foliar/colmo, por período de avaliação, tratamento e médias, em pastagem de milheto sob pastejo contínuo de novilhas de corte (experimento 1)

Table 2 - Leaf/stem proportion (\%) and leaf blade/stem relation, by evaluation period, treatment and means, in pearl millet pasture under with beef heifers under continuous grazing (experiment 1)

\begin{tabular}{lcccc}
\hline Tratamento (Treatment) & $16 / 02 \mathrm{a} 09 / 03$ & $10 / 03 \mathrm{a} 30 / 03$ & $31 / 03 \mathrm{a} 21 / 04$ & Média $($ Mean) \\
\hline PAST $_{1}($ GRASS $)$ & $79 / 21(3,7)$ & $43 / 57(0,8)$ & $41 / 59(0,7)$ & $54 / 46(1,2)$ \\
PAST $_{1} / \mathrm{M}\left(\right.$ GRASS $\left._{1} / C\right)$ & $75 / 25(3,0)$ & $51 / 49(1,0)$ & $30 / 70(0,4)$ & $52 / 48(1,1)$ \\
PAST $_{1} / \mathrm{P}($ GRASS $/ P)$ & $87 / 13(6,6)$ & $60 / 40(1,5)$ & $40 / 60(0,7)$ & $62 / 38(1,6)$ \\
Média $($ Mean $)$ & $80 / 20(4,0) \mathrm{a}$ & $51 / 49(1,0) \mathrm{b}$ & $37 / 63(0,6) \mathrm{c}$ & $56 / 44(1,3)$ \\
\hline
\end{tabular}

Tabela 3 - Valores médios de digestibilidade in vitro da matéria orgânica (DIVMO), conteúdo de energia metabolizável (EM) e conteúdo de proteína bruta $(\mathrm{PB})$ da forragem aparentemente consumida e dos suplementos (experimento 1)

Table 3 - Average values of organic matter in vitro digestibility (OMIVD), metabolizable energy content (ME) and crude protein content $(C P)$ of the apparent consumed forage and supplements (experiment 1)

\begin{tabular}{|c|c|c|c|}
\hline & $\begin{array}{l}\operatorname{DIVMO}(\%) \\
\text { OMIVD }(\%)\end{array}$ & $\begin{array}{c}\mathrm{EM}(\mathrm{Mcal} / \mathrm{kg} \mathrm{MS}) \\
M E(\text { Mcal/kg DM) }\end{array}$ & $\begin{array}{l}\mathrm{PB}(\mathrm{kg} / \mathrm{kg} \mathrm{MS}) \\
C P(\mathrm{~kg} / \mathrm{kg} D M)\end{array}$ \\
\hline $\begin{array}{l}\text { Milheto PAST } \\
\text { Pearl millet } G R A S S_{1}\end{array}$ & 60,2 & 1,99 & 0,172 \\
\hline $\begin{array}{l}\text { Milheto PAST } 1 / \mathrm{M}^{1} \\
\text { Pearl millet GRASS } S_{1} / C\end{array}$ & 62,4 & 2,06 & 0,166 \\
\hline $\begin{array}{l}\text { Milheto PAST }_{1} / \mathrm{P}^{1} \\
\text { Pearl millet GRASS } / P\end{array}$ & 62,8 & 2,11 & 0,160 \\
\hline $\begin{array}{l}\text { Média } \\
\text { Mean }\end{array}$ & 61,8 & 2,05 & 0,166 \\
\hline $\begin{array}{l}\text { Grão de milho + uréia } \\
\text { Corn grain + urea }\end{array}$ & 76,8 & 2,74 & 0,120 \\
\hline $\begin{array}{l}\text { Polpa cítrica + uréia } \\
\text { Citric pulp + urea }\end{array}$ & 80,3 & 2,86 & 0,120 \\
\hline
\end{tabular}

e mantidas exclusivamente em pastagem de milheto, com GDM de 0,257 kg. Gomes et al. (1986) verificaram que bezerros desmamados aos 101 dias e mantidos em pastagem de milheto obtiveram GDM de $0,441 \mathrm{~kg}$, valor inferior ao ganho obtido pelo grupo mantido ao pé da vaca (média de $0,542 \mathrm{~kg}$ ). Resultados semelhantes foram relatados por Restle et al. (1992), com GDM de 0,302 kg para bezerros desmamados aos 90 dias e mantidos em pastagem de milheto, enquanto bezerros mantidos sob amamentação, em campo nativo, obtiveram ganho de $0,450 \mathrm{~kg} / \mathrm{dia}$. Os resultados citados sugerem que este diferencial no desempenho somente seria alcançado com a utilização de suplementos concentrados. Isto se confirmou no presente trabalho, quando o uso exclusivo da pastagem, mesmo de alta qualidade como o milheto, não assegurou que as novilhas apresentassem desempenho similar ao normalmente verificado em animais amamentados até os seis/sete meses de idade, o que seria fundamental para o acasalamento das novilhas aos 14 meses. Conforme

R. Bras. Zootec., v.34, n.1, p.209-219, 2005
Fox et al. (1988), novilhas com peso adulto entre 400 e $467 \mathrm{~kg}$ devem apresentar, até os sete meses, GDM entre 0,6 e $0,68 \mathrm{~kg}$, para que atinjam peso ótimo para o primeiro cio aos 426 dias de idade. Para os sistemas 18 ou 24 meses ainda admite-se ganhos mais baixos nesta fase, desde que o desenvolvimento corporal dos animais não seja prejudicado.

As melhores taxas de ganho de peso verificadas nos animais suplementados permitiram que as novilhas chegassem no outono com peso vivo e condição corporal superiores $(\mathrm{P}<0,05)$ em relação aos valores observados para estas variáveis com o uso exclusivo de pastagem. Ainda assim, o peso final médio em $\mathrm{PAST}_{1} / \mathrm{M}$ e $\mathrm{PAST}_{1} / \mathrm{P}$ de 134,1 kg, aos 163 dias de idade das novilhas, foi inferior ao peso mínimo crítico relatado por Moraes \& Lobato (1993), de $143 \mathrm{~kg}$ aos 150 dias, para que novilhas alcancem o primeiro serviço aos 14-15 meses, com a utilização de pastagens melhoradas na recria. Novilhas que receberam grão de milho ou polpa cítrica obtiveram, em 63 dias de pastejo, incremento no escore de condição corporal de 
0,3 pontos, praticamente atingindo o estádio de plena deposição muscular (Lowman et al., 1973). Este resultado torna-se bastante expressivo, em se tratando de animais muito jovens e já desmamados, nos quais acúmulo de tecido adiposo dificilmente é observado.

Os valores estimados de digestibilidade in vitro da matéria orgânica (DIVMO), conteúdo de proteína bruta (PB) e energia metabolizável (EM) da forragem aparentemente consumida e dos suplementos constam da Tabela 3. Não se detectou diferença para essas variáveis $(\mathrm{P}>0,05)$ entre as médias das amostras de simulação do pastejo nos diferentes tratamentos. A pastagem apresentou elevado conteúdo de $\mathrm{PB}$, enquanto para grão de milho e polpa cítrica foram registrados valores mais altos de DIVMO e conteúdo de EM.

Os valores estimados pelo NRC (1984) para consumo de matéria seca (CMS) e exigências diárias de $\mathrm{EM}$ e $\mathrm{PB}$, para taxas de GDM semelhantes às verificadas no experimento 1, encontram-se na Tabela 4.

Admitindo se a predição do consumo de MS feita pelo NRC (1984) para ganho diário de $0,4 \mathrm{~kg}$, o aporte energético fornecido aos animais mantidos exclusivamente a pasto ( PAST $_{1}$ ) está de acordo com o GDM de 0,376 kg observado neste tratamento. Partindo do mesmo princípio, observou-se, no entanto, excedente no consumo estimado de PB $(0,052 \mathrm{~kg}$ $\mathrm{PB} / \mathrm{kg}$ MS consumido), que seria suficiente para atender à exigência deste nutriente na faixa de ganho de peso dos animais suplementados.

Neste caso, a energia foi um fator limitante do desempenho animal. Parte do aporte protéico excedente pode, ainda, ter contribuído para amenizar possível déficit energético ocorrido em $\mathrm{PAST}_{1}$. Segundo Andriguetto (1981), no processo de catabolização, o excesso de proteína é desaminado e a cadeia carbonada é utilizada como fonte de energia, com aproveitamento próximo a $60 \%$. Em $\mathrm{PAST}_{1} / \mathrm{Me}$ $\mathrm{PAST}_{1} / \mathrm{P}$, a menor contribuição em $\mathrm{PB}$ do grão de milho e da polpa cítrica corrigidos com NNP, em relação à pastagem de milheto, ocasionou maior equilíbrio entre o nível protéico exigido pelos animais e o fornecido pela dieta. Para estes tratamentos, o acréscimo no conteúdo de EM dos suplementos em relação à pastagem, por si só, não explica o desempenho observado nos animais que receberam suplementação. Mesmo considerando-se uma substituição total do consumo de forragem por suplemento, mantendo-se constante o valor predito pelo NRC (1984) para consumo total de MS, a pastagem poderia fornecer às novilhas 5,34 Mcal/dia, o que ainda acarretaria em déficit energético de 1,08 e 0,95 Mcal/ dia, respectivamente, para $\mathrm{PAST}_{1} / \mathrm{M}$ e $\mathrm{PAST}_{1} / \mathrm{P}$. Apesar de o GDM previsto pelo NRC (1984) para este aporte de nutrientes encontrar-se um pouco acima dos valores observados, a principal explicação para o desempenho dos animais suplementados, com aporte energético aparentemente inferior ao exigido, está relacionada com dois fatores:

i) a taxa de substituição ( $\mathrm{kg}$ MS de forragem $/ \mathrm{kg}$ MS de suplemento) não é total, e provavelmente a suplementação com grão de milho ou polpa cítrica promoveu aumento no consumo total de MS pelos animais, eliminando o déficit energético.

ii) A inclusão de suplementos ricos em carboidratos

Tabela 4 - Exigências diárias de consumo de matéria seca (CMS), energia metabolizável (EM) e proteína bruta (PB) para GDM de 0,4 e 0,6 kg em novilhas de corte aos $135 \mathrm{~kg}$ de PV (NRC, 1984). Aporte de nutrientes realizado via suplemento em $\mathrm{PAST}_{1} / \mathrm{M}$ e $\mathrm{PAST}_{1} / \mathrm{P}$ (experimento 1)

Table 4 - Daily requirements of dry matter intake (DMI), metabolizable energy (ME) and crude protein (CP) for ADG of .4 and .6 $\mathrm{kg}$ in beef heifers at $135 \mathrm{~kg}$ of $L W(N R C, 1984)$. Nutrient intake offered by supplement in GRASS $1 / C$ and GRASS $1 / P$ (experiment 1)

\begin{tabular}{|c|c|c|c|}
\hline & $\begin{array}{l}\text { CMS (kg) } \\
D M I(k g)\end{array}$ & $\begin{array}{c}\mathrm{EM}(\mathrm{Mcal} / \mathrm{kg} \mathrm{MS}) \\
M E(\text { Mcal/kg DM) }\end{array}$ & $\begin{array}{l}\text { PB }(\mathrm{kg} / \mathrm{kg} \mathrm{MS}) \\
D M I(\mathrm{~kg} / \mathrm{kg} \mathrm{DM})\end{array}$ \\
\hline & & $\begin{array}{l}\text { Exigências NRC } \\
\text { NRC requirements }\end{array}$ & \\
\hline \multirow{4}{*}{$\begin{array}{l}\text { GDM } 0,4 \mathrm{~kg} / \text { animal } \\
\text { ADG } 0,4 \mathrm{~kg} / \text { animal } \\
\text { GDM } 0,6 \mathrm{~kg} / \text { animal } \\
A D G 0.6 \mathrm{~kg} / \text { animal }\end{array}$} & 3,624 & 2,252 & 0,114 \\
\hline & & 404 & 0131 \\
\hline & $3, / 18$ & 2,494 & 0,131 \\
\hline & & $\begin{array}{l}\text { Suplementos } \\
\text { Supplements }\end{array}$ & \\
\hline Grão de milho (Corn grain) & 1,033 & 2,74 & 0,120 \\
\hline Polpa cítrica (Citric pulp) & 1,034 & 2,86 & 0,120 \\
\hline
\end{tabular}

R. Bras. Zootec., v.34, n.1, p.209-219, 2005 
em uma dieta-base com elevado conteúdo de PB, como a pastagem de milheto, pode ter contribuído para melhor eficiência na captura de amônia $\left(\mathrm{NH}_{3}\right)$ em nível ruminal, beneficiando o aporte de nutrientes pelos animais e aumentando o ganho de peso.

A primeira consideração está respaldada por Rearte \& Pieroni (2001), em que a suplementação de concentrados para animais em pastejo acarreta decréscimo na ingestão de forragem, mas normalmente o consumo total de MS e o consumo de energia são aumentados. Minson (1990) revisou 19 trabalhos com diferentes categorias animais em pastejo recebendo suplementação e registrou taxa de substituição média de 0,69. Isto significa que a fração de forragem não-consumida por unidade de suplemento fornecida, juntamente com o maior valor energético deste, serão responsáveis por um efeito aditivo sobre o consumo de MS e o ganho de peso.

O segundo fator mencionado refere-se à hipótese de haver maior sincronismo entre a liberação de energia e $\mathrm{NH}_{3}$ para a produção de proteína microbiana, quando concentrados energéticos são incluídos em dietas à base de forragens (Poppi \& McLennan, 1995). Segundo Lana \& Gomes Jr. (2002), existe a necessidade de se desenvolver equações para estimar o efeito associativo dos suplementos sobre o consumo de plantas forrageiras. É importante salientar, no entanto, que a presente discussão não pretende questionar os valores preditos pelo NRC (1984), mas contribuir para o entendimento das relações pastagem-animal-suplemento, visando maximizar o desempenho produtivo de novilhas em fase de recria.

No experimento 2, massa e oferta de forragem não diferiram entre tratamentos e entre períodos (P>0,05), com valores médios de $1333,3 \mathrm{~kg} /$ ha de MS e $10,5 \%$ do PV, respectivamente. Na Tabela 5, são apresentados os resultados de GDM, PV e ECC, por tratamento e período experimental, correspondentes à utilização da pastagem de aveia preta e azevém. Não houve diferença entre os tratamentos para peso e condição corporal iniciais dos animais $(\mathrm{P}>0,05)$, sendo respectivamente de $109,5 \mathrm{~kg}$ e 2,55 pontos. Foi observada interação $(\mathrm{P}<0,05)$ entre tratamento e período apenas para a variável ECC.

Os animais apresentaram GDM superior $(\mathrm{P}<0,05)$ no período inicial de pastejo. Os ganhos foram bastante elevados em todos os tratamentos, consideran-

Tabela 5 - Ganho de peso diário médio (GDM), peso vivo (PV) e escore de condição corporal (ECC) das novilhas, por tratamento e período (experimento 2)

Table 5 - Average daily gain (ADG), live weight (LW) and body condition score (BCS) of beef heifers, per treatment and period (experiment 2)

\begin{tabular}{|c|c|c|c|c|}
\hline \multirow{2}{*}{$\begin{array}{l}\text { Tratamento } \\
\text { Treatment }\end{array}$} & \multicolumn{3}{|c|}{$\begin{array}{c}\text { Período } \\
\text { Period }\end{array}$} & \multirow{2}{*}{$\begin{array}{l}\text { Média } \\
\text { Mean }\end{array}$} \\
\hline & $13 / 07$ a $10 / 08$ & $11 / 08$ a 07/09 & 08/09 a 09/10 & \\
\hline \multicolumn{5}{|c|}{ GDM (kg/animal) } \\
\hline & & $A D G(\mathrm{~kg} /$ animal $)$ & & \\
\hline $\mathrm{PAST}_{2}\left(G R A S S_{2}\right)$ & $1,145 \mathrm{abA}$ & $0,780 \mathrm{~B}$ & $0,580 \mathrm{bB}$ & $0,835 b$ \\
\hline $\mathrm{PAST}_{2} / \mathrm{M}\left(G R A S S_{2} / C\right)$ & $1,050 \mathrm{bA}$ & $0,940 \mathrm{~B}$ & $0,915 \mathrm{aB}$ & $0,968 \mathrm{ab}$ \\
\hline $\mathrm{PAST}_{2}^{2} / \mathrm{C}\left(G R A S S_{2}^{2} / H\right)$ & $1,425 \mathrm{aA}$ & $0,950 \mathrm{~B}$ & $0,960 \mathrm{aB}$ & $1,112 \mathrm{a}$ \\
\hline Média (Mean) & $1,207 \mathrm{~A}$ & $0,890 \mathrm{~B}$ & $0,818 \mathrm{~B}$ & 0,972 \\
\hline \multicolumn{5}{|c|}{$\mathrm{PV}(\mathrm{kg} / \mathrm{animal})$} \\
\hline \multicolumn{5}{|c|}{$L W(\mathrm{~kg} /$ animal $)$} \\
\hline $\mathrm{PAST}_{2}\left(G R A S S_{2}\right)$ & $144,0 \mathrm{aC}$ & $165,8 \mathrm{bB}$ & $184,3 \mathrm{bA}$ & 164,7 \\
\hline $\mathrm{PAST}_{2} / \mathrm{M}\left(G R A S S_{2} / C\right)$ & $136,7 \mathrm{bC}$ & $163,0 \mathrm{bB}$ & $192,3 \mathrm{abA}$ & 164,0 \\
\hline $\mathrm{PAST}_{2} / \mathrm{C}\left(G R A S S_{2} / H\right)$ & $149,3 \mathrm{aC}$ & $176,0 \mathrm{aB}$ & $206,7 \mathrm{aA}$ & 177,3 \\
\hline Média (Mean) & $143,3 \mathrm{C}$ & $168,3 \mathrm{~B}$ & $194,4 \mathrm{~A}$ & 168,7 \\
\hline \multicolumn{5}{|c|}{$\operatorname{ECC}(1-5)^{*}$} \\
\hline \multicolumn{5}{|c|}{$B C S(1-5) *$} \\
\hline $\operatorname{PAST}_{2}\left(G R A S S_{2}\right)$ & $2,80 \mathrm{~d}$ & $2,80 \mathrm{~d}$ & $2,75 \mathrm{de}$ & 2,78 \\
\hline $\mathrm{PAST}_{2} / \mathrm{M}\left(G R A S S_{2} / C\right)$ & $2,70 \mathrm{e}$ & $2,90 \mathrm{c}$ & $2,90 \mathrm{c}$ & 2,83 \\
\hline $\mathrm{PAST}_{2} / \mathrm{C}\left(G R A S S_{2} / H\right)$ & $2,90 \mathrm{c}$ & $3,10 \mathrm{~b}$ & $3,20 \mathrm{a}$ & 3,07 \\
\hline Média (Mean) & 2,80 & 2,93 & 2,95 & 2,89 \\
\hline
\end{tabular}

Médias seguidas de letras minúsculas distintas, na coluna, diferem $(P<0,05)$ estatisticamente.

Médias seguidas de letras maiúsculas distintas, na linha, diferem $(P<0,05)$ estatisticamente.

*Médias seguidas de letras distintas diferem $(P<0,05)$ estatisticamente.

Means followed of distinct small letters, in column, are different $(P<.05)$ statisticaly.

Means followed of distinct capital letters, in line, are different $(P<.05)$ statisticaly.

*Means followed of distinct letters are different $(P<.05)$ statisticaly.

R. Bras. Zootec., v.34, n.1, p.209-219, 2005 
do-se que não houve período de adaptação. Esta resposta se justifica provavelmente pela forte restrição alimentar sofrida pelas novilhas nos dois meses que antecederam o experimento, quando permaneceram em campo nativo e apresentaram perda de peso (-0,225 kg/animal). Ryan (1990) definiu 'crescimento compensatório' como a taxa de crescimento superior à normal, observada após um período em que uma restrição alimentar é imposta aos animais. Segundo Fox et al. (1972), o crescimento compensatório envolve a redução na exigência de megacalorias para mantença e o aumento na eficiência do uso da energia metabolizável acima da mantença. Este aspecto pode ter contribuído para que os animais mantidos exclusivamente a pasto $\left(\mathrm{PAST}_{2}\right)$ tenham obtido da forragem aporte de nutrientes suficiente para a realização de ganhos semelhantes ao de animais suplementados. No período de $13 / 07$ a $10 / 08$, foi observada diferença no GDM

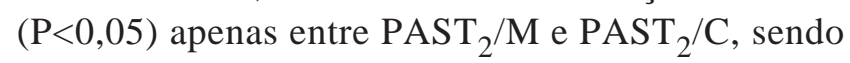
que os animais de $\mathrm{PAST}_{2}$ obtiveram ganho intermediário. O melhor desempenho médio de animais suplementados com casca de soja, em relação ao uso do grão de milho, provavelmente está ligado a modificações menos bruscas no ambiente ruminal proporcionada por este tipo de alimento. Segundo Tambara et al (1995), por apresentar alto conteúdo de fibra efetiva, a casca de soja estimula a salivação, a ruminação e mantém um ambiente ruminal satisfatório. A partir do segundo período, os animais suplementados com grão de milho ou casca de soja passaram a apresentar valores de GDM bastante similares $(\mathrm{P}>0,05)$ e, no período final de pastejo, superaram em
61,7\% ( $\mathrm{P}<0,05)$ o ganho apresentado em $\mathrm{PAST}_{2}$.

No experimento 2, a queda na qualidade da forragem aparentemente consumida foi a principal responsável pelo maior GDM dos animais suplementados no final do ciclo de pastejo em relação aos nãosuplementados $\left(\mathrm{PAST}_{2}\right)$. Constam da Tabela 6 os resultados referentes à qualidade da forragem coletada via simulação do pastejo animal. Os valores de DIVMO, PB e EM não diferiram entre os tratamentos $(\mathrm{P}>0,05)$. Na média dos tratamentos, no entanto, existiu diferença entre os períodos experimentais.

As exigências nutricionais de novilhas em crescimento compensatório (NRC, 1984) e a composição em EM e PB dos suplementos utilizados no segundo experimento são apresentadas na Tabela 7 .

O conteúdo de PB da forragem aparentemente consumida pelos animais não foi limitante para ganhos elevados em nenhum momento do ciclo de pastejo. Até mesmo no tratamento $\mathrm{PAST}_{2} / \mathrm{M}$, onde o grão de milho apresentou valor muito baixo para este nutriente, provocando maior quebra na PB da dieta total, a pastagem assegurou teor de $\mathrm{PB}$ na dieta próximo a $15 \%$, suficiente para promover taxas de ganho de peso superiores a $1,0 \mathrm{~kg} / \mathrm{animal} / \mathrm{dia}$. A exemplo do experimento 1 , verificou-se déficit no fornecimento de energia via forragem, que atendeu às exigências das novilhas para este nutriente apenas no período inicial. A partir daí, o maior valor energético dos suplementos, juntamente com a possibilidade de aproveitamento de parte do excedente de proteína, como fonte de energia e aumento no consumo total de MS, passariam a ser os responsáveis pela manutenção de ganhos elevados pelos animais suplementados. $\mathrm{Na}$

Tabela 6 - Valores médios de digestibilidade in vitro da matéria orgânica (DIVMO), conteúdo de energia metabolizável (EM) e conteúdo de proteína bruta (PB) da forragem aparentemente consumida pelos animais, por tratamento e período (experimento 2)

Table 6 - Average values of organic matter in vitro digestibility (OMIVD), metabolizable energy content (ME) and crude protein content $(C P)$ of the animals consumed seemingly forage, per treatment and period (experiment 2)

\begin{tabular}{|c|c|c|c|c|}
\hline Parâmetro Parameter & $13 / 07$ a $10 / 08$ & $11 / 08$ a 07/09 & $12 / 08$ a $09 / 10$ & Média (Mean) \\
\hline $\begin{array}{l}\text { DIVMO (\%)* } \\
\text { OMIVD (\%) }\end{array}$ & $76,0 \mathrm{a}$ & $62,1 \mathrm{~b}$ & $59,7 \mathrm{~b}$ & 65,9 \\
\hline $\begin{array}{l}\mathrm{EM}(\mathrm{Mcal} / \mathrm{kg} \mathrm{MS})^{* *} \\
M E(\text { Mcal/kg DM })\end{array}$ & $2,507 \mathrm{a}$ & $2,046 \mathrm{~b}$ & $1,954 b$ & 2,169 \\
\hline $\begin{array}{l}\mathrm{PB}(\mathrm{kg} / \mathrm{kg} \mathrm{MS})^{* * * *} \\
C P(\mathrm{~kg} / \mathrm{kg} D M)\end{array}$ & $0,227 \mathrm{a}$ & $0,183 b$ & $0,162 \mathrm{c}$ & 0,191 \\
\hline
\end{tabular}

Médias seguidas de letras distintas, na linha, diferem estatisticamente $(P<0,05)$.

Means folowed by distinct letters, in line, are different statisticaly $(P<.05)$.

${ }^{*} \mathrm{y}=79,456-0,1761 x ; R^{2}=0,58$.

$* * \quad y=2,711-0,0063 x ; R^{2}=0,73$.

${ }^{* * *} y=22,985-0,0782 x ; R^{2}=0,81$.

R. Bras. Zootec., v.34, n.1, p.209-219, 2005 
Tabela 7 - Exigências diárias de consumo de matéria seca (CMS), energia metabolizável (EM) e proteína bruta (PB), para ganho de 0,9 e $1,1 \mathrm{~kg} /$ dia em novilhas de corte (NRC, 1984). Aporte de nutrientes proporcionado via grão de milho ou casca de soja

Table 7 - Daily requirements of dry matter intake (DMI), metabolizable energy (ME) and crude protein (CP), for ADG of .9 and $1.1 \mathrm{~kg}$ in beef heifers (NRC, 1984). Nutrient intake offered by corn grain and soy hull

\begin{tabular}{|c|c|c|c|}
\hline & $\begin{array}{l}\text { CMS (kg) } \\
D M I(k g)\end{array}$ & $\begin{array}{c}\mathrm{EM}(\mathrm{Mcal} / \mathrm{kg} \mathrm{MS}) \\
M E(\text { Mcal/kg DM) }\end{array}$ & $\begin{array}{r}\mathrm{PB}(\mathrm{kg} / \mathrm{kg} \mathrm{MS}) \\
C P(\mathrm{~kg} / \mathrm{kg} D M)\end{array}$ \\
\hline & & $\begin{array}{l}\text { Exigências NRC } \\
\text { NRC requirements }\end{array}$ & \\
\hline \multirow{4}{*}{$\begin{array}{l}\text { GDM } 0,9 \mathrm{~kg} / \text { animal } \\
\text { ADG } .9 \mathrm{~kg} / \text { animal } \\
\text { GDM } 1,1 \mathrm{~kg} / \text { animal } \\
A D G 1.1 \mathrm{~kg} / \text { animal }\end{array}$} & 5,020 & 2,516 & 0,125 \\
\hline & & & \\
\hline & 4,890 & 2,781 & 0,141 \\
\hline & & $\begin{array}{l}\text { Suplementos } \\
\text { Supplements }\end{array}$ & \\
\hline Grão de milho (Corn grain) & 1,425 & 2,73 & 0,072 \\
\hline Casca de soja (Soy hull) & 1,357 & 2,49 & 0,132 \\
\hline
\end{tabular}

média dos períodos, a suplementação com casca de soja proporcionou GDM superior ao obtido com uso exclusivo da pastagem de aveia e azevém $(\mathrm{P}<0,05)$, ficando a suplementação com grão de milho em posição intermediária entre os dois $(\mathrm{P}>0,05)$. $\mathrm{O}$ tratamento $\mathrm{PAST}_{2} / \mathrm{C}$ apresentou ainda maior incremento na condição corporal ao longo do experimento 2 em relação aos demais $(\mathrm{P}<0,05)$, sendo o único tratamento em que o escore médio dos animais aumentou em todos os períodos. Os animais suplementados com grão de milho $\left(\mathrm{PAST}_{2} / \mathrm{M}\right)$ também apresentaram ECC superior aos de $\mathrm{PAST}_{2}(\mathrm{P}<0,05)$.

A análise do desempenho seqüencial das novilhas no primeiro ano em recria é apresentada na Tabela 8 , incluindo os experimentos $1 \mathrm{e} 2 \mathrm{e}$ o período intermediário entre ambos. Não existiu diferença para PV e ECC iniciais $(\mathrm{P}>0,05)$. Novilhas suplementadas nas pastagens de verão e de inverno ou somente no inverno apresentaram, aos 12 meses de idade, $\mathrm{GDM}_{3-12}$, PVf e ECCf superiores aos observados em animais mantidos exclusivamente a pasto. Considerando-se as taxas de ganho de peso estimadas para cada sistema de acasalamento (14, 18 ou 24 meses), no entanto, nenhum dos grupos chegou ao final do inverno com peso suficiente para viabilizar o acasalamento aos 14 meses de idade. O bom desempenho das novilhas na pastagem de aveia e azevém não foi suficiente para compensar a perda de peso ocorrida durante a fase de estabelecimento da pastagem de inverno. Rocha \& Lobato (2002) afirmam que o período de outono/início do inverno, no Rio Grande do Sul (RS), quando as pastagens naturais já cessaram seu crescimento e as pasta- gens cultivadas de estação fria ainda não proporcionam condições de pastejo, constitui a principal limitação para alcançar taxas de crescimento anual das novilhas que permitam o seu ingresso no sistema 'um ano'. Segundo Pötter et al. (2000), a habilidade dos bovinos em realizarem ganho compensatório após período de restrição é uma ferramenta muito utilizada nos sistemas que prevêem o acasalamento das fêmeas aos 24 ou aos 36 meses. Quando a idade pretendida ao primeiro acasalamento é de quatorze meses, esta prática não é eficiente do ponto de vista do desenvolvimento dos animais.

Durante o período em que permaneceram em pastagens cultivadas (63 dias no experimento 1 e 88 dias no experimento 2), animais que receberam suplemento em pelo menos uma das épocas obtiveram, em média, ganho de peso de $118,1 \mathrm{~kg}$. Descontando-se a perda média de $18,7 \mathrm{~kg}$ ocorrida no período intermediário, obtém-se ganho de aproximadamente $100 \mathrm{~kg}$ por animal, no período de $16 \mathrm{de}$ fevereiro s 09 de outubro de 2001. A partir desta data, ainda faltariam aproximadamente 40 dias para o início da estação de acasalamento (15/11). Isto permite afirmar que, se tivessem recebido tratamento alimentar suficiente para ganhos moderados durante a fase correspondente ao estabelecimento da pastagem de inverno, estas novilhas poderiam atingir o peso mínimo crítico para o acasalamento aos 14 meses de idade.

Beretta \& Lobato (1998) observaram que novilhas cruzas Hereford e Aberdeen Angus apresentaram atividade cíclica aos 14 meses com 254 kg e ECC de 3,10 pontos ( 1 a 5 ). 
Tabela 8 - Ganho de peso diário médio (GDM) de novilhas de corte dos 3 aos 12 meses e estimativas de GDM para acasalamento aos 14, 18 ou 24 meses de idade. Médias de peso vivo e condição corporal no início (PVi e ECCi) e final (PVf e ECCf) do período de avaliações

Table 8 - Average daily gain (ADG) of beef heifers, of the 3 at 12 months and ADG estimatives to mating at 14,18 or24 months of age. Means of live weight and body condition in the start (LWS and BCSs) and end (LWf and BCSf) of the evaluations

\begin{tabular}{|c|c|c|c|c|}
\hline $\begin{array}{l}\text { Tratamento } \\
\text { Treatment }\end{array}$ & $\begin{array}{l}\mathrm{GDM}_{3-12}(\mathrm{~kg}) \\
A D G_{3-12}(\mathrm{~kg})\end{array}$ & $\begin{array}{c}\mathrm{GDM}_{12-14}(\mathrm{~kg}) \\
A D G_{12-14}(\mathrm{~kg})\end{array}$ & $\begin{array}{c}\mathrm{GDM}_{12-18}(\mathrm{~kg}) \\
A D G_{12-18}(\mathrm{~kg})\end{array}$ & $\begin{array}{c}\mathrm{GDM}_{12-24}(\mathrm{~kg}) \\
A D G_{12-24}(\mathrm{~kg})\end{array}$ \\
\hline SUPL 1 e 2 (SUPPL 1 and 2 ) & $0,462 \mathrm{a}$ & 1,756 & 0,374 & 0,175 \\
\hline SUPL 1 (SUPPL 1) & $0,340 \mathrm{ab}$ & 2,368 & 0,504 & 0,236 \\
\hline SUPL 2 (SUPPL 2) & $0,426 a$ & 2,075 & 0,441 & 0,206 \\
\hline \multirow[t]{3}{*}{ N-SUPL $(N-S U P P L)$} & $0,167 b$ & 3,525 & 0,750 & 0,351 \\
\hline & $\operatorname{PVi}(\mathrm{kg})$ & $\operatorname{ECCi}(1-5)$ & $\operatorname{PVf}(\mathrm{kg})$ & $\operatorname{ECCf}(1-5)$ \\
\hline & $L W s(k g)$ & $\operatorname{BCSs}(1-5)$ & $L W f(k g)$ & $B C S f(1-5)$ \\
\hline SUPL 1 e 2 (SUPPL 1 and 2) & 94,2 & 2,69 & $202,7 \mathrm{a}$ & $3,11 \mathrm{a}$ \\
\hline SUPL 1 (SUPPL 1) & 98,3 & 2,57 & $178,3 \mathrm{ab}$ & $2,76 a b$ \\
\hline SUPL 2 (SUPPL 2) & 90,0 & 2,58 & $190,0 \mathrm{a}$ & $3,07 \mathrm{a}$ \\
\hline NSUPL (NSUPPL) & 92,8 & 2,54 & $132,0 \mathrm{~b}$ & $2,16 b$ \\
\hline
\end{tabular}

Médias seguidas de letras distintas, na coluna, diferem estatisticamente $(P<0,05)$.

Means followed by distinct letters, in column, statisticaly differ $(P<.05)$.

SUPL 1 e 2 - novilhas suplementadas nos experimentos 1 e 2 (SUPPL 1 and 2 - heifers supplemented in experiments 1 and 2).

SUPL 1 - novilhas suplementadas somente no experimento1 (SUPPL 1 - heifers supplemented only experiment 1).

SUPL 2 - novilhas suplementadas somente no experimento 2 (SUPPL 2 - heifers supplemented only experiment 2).

N-SUPL - novilhas mantidas exclusivamente a pasto ( $N$-SUPPL - heifers maintained exclusively at grassland).

No que se refere aos sistemas ' 18 ' ou '24 meses', os ganhos verificados em SUPL 1 e 2 , SUPL 1 e SUPL 2 representam taxa média de crescimento adequada. Para peso adulto de $420 \mathrm{~kg}$ e peso à puberdade igual a $65 \%$ deste valor (Patterson et al., 1992), o GDM necessário no segundo ano de vida das novilhas pertencentes a estes grupos seria, em média, de $0,440 \mathrm{~kg}$ e $0,206 \mathrm{~kg}$, para que fossem acasaladas, respectivamente, aos 18 (15/04) ou 24 (15/11) meses de idade. No Rio Grande do Sul, estes ganhos podem ser facilmente obtidos com as novilhas manejadas exclusivamente em campo nativo. Neste caso, o investimento em alimentação de qualidade no primeiro ano de vida das novilhas teria assegurado desenvolvimento corporal adequado aos animais, além de permitir maior flexibilidade no planejamento alimentar para os períodos subseqüentes até o acasalamento. Para animais que não receberam suplemento em nenhum dos experimentos (NSUPL), a utilização de pastagens cultivadas assegurou a possibilidade de redução na idade ao primeiro acasalamento para 24 meses. O ingresso dessas novilhas no sistema ' 18 meses', no entanto, ainda dependeria da utilização de uma dieta alimentar de maior qualidade que o campo nativo na estação estival subseqüente. Segundo Moojen (1991), o campo nativo do RS apresenta potencial para ganho de peso próximo a $0,5 \mathrm{~kg} / \mathrm{animal} / \mathrm{dia}$ durante o período de setembro a abril.

\section{Conclusões}

A suplementação energética em pastagem de milheto é uma alternativa viável para que novilhas desmamadas aos 60-90 dias apresentem desempenho individual satisfatório no período inicial pós-desmama.

$\mathrm{O}$ fornecimento de suplementos energéticos durante a utilização da pastagem de verão e/ou da pastagem de inverno, no primeiro ano de recria, permite desenvolvimento satisfatório para o primeiro serviço das novilhas aos 18 ou 24 meses.

Do ponto de vista nutricional, os subprodutos polpa cítrica e casca de soja podem substituir o grão de milho como suplemento energético para recria de novilhas de corte.

\section{Literatura Citada}

ANDRIGUETTO, J.M. Nutrição animal. 4.ed. São Paulo: Nobel, v.1. 1981. 396p.

ASSOCIATION OF OFFICIAL ANALYTICAL CHEMISTS AOAC. Official methods of analysis. 14.ed. Washington, D.C.: 1984. 1141p.

BERETTA, V.; LOBATO, J.F.P. Sistema 'um ano' de produção de carne: avaliação de estratégias alternativas de alimentação hibernal de novilhas de reposição. Revista Brasileira de Zootecnia, v.27, n.1, p.157-163, 1998.

CARVALHO,P.C.F.; MARÇAL, G.K.; RIBEIRO FILHO, H.M.N. et al. Pastagens altas podem limitar o consumo dos animais. In: REUNIÃO ANUAL DA SOCIEDADE BRASILEIRA DE ZOOTECNIA, 38., 2001, Piracicaba. Anais... Piracicaba: Sociedade Brasileira de Zootecnia, 2001, CD-ROM. 
CATON, J.S.; DHUYVETTER, D.V. Influence of energy supplementation on grazing ruminants: requirements and responses. Journal of Animal Science, v.75, p.533$542,1997$.

EUCLIDES, V.P.B; MACEDO, M.C.M.; OLIVEIRA, M.P. Avaliação de diferentes métodos de amostragem sob pastejo. Revista Brasileira de Zootecnia, v.21, n.4, p.691-702, 1992.

FOX, D.G.; JOHNSON, R.R.; PRESTON, R.L. et al. Protein and energy utilization during compensatory growth in beef cattle. Journal of Animal Science, v.38, p.437-445, 1972.

FOX, D.G.; SNIFFEN, C.J.; O'CONNOR, J.D. Adjusting nutrient requirements of beef cattle for animal and environmental variations. Journal of Animal Science, v.66, p.1475-1495, 1988.

GARDNER, A.L. Técnicas de pesquisa em pastagens e aplicabilidade de resultados em sistemas de produção. Brasília: IICA/EMBRAPA-CNPGL, 1986. 197p. (Série Publicações Miscelâneas, 634).

GOMES, J.B.; RESTLE, J.; MOOJEN, E.L. et al. Efeito da época da desmama e da pastagem no desempenho de vacas e terneiros de corte. In: REUNIÃO ANUAL DA SOCIEDADE BRASILEIRA DE ZOOTECNIA, 23., 1986, Campo Grande. Anais... Campo Grande: Sociedade Brasileira de Zootecnia, 1986. p.366.

LANA, R.P.; GOMES JR., P. Sistema de suplementação alimentar para bovinos de corte em pastejo. Validação. Revista Brasileira de Zootecnia, v.31, n.1, p.451-459, 2002 (suplemento).

LOWMAN, B.G.; SCOTT, N.; SOMERVILLE, S. Condition scoring beef cattle. Edinburgh: East of Scotland College of Agriculture, 1973. 8p.

MINISTRY OF AGRICULTURE, FISCHERIES AND FOOD - MAFF. Energy allowances and feed systems for ruminants. London, 1977. 79p. (Technical Bulletin, 33).

MINSON, D.L. Forage in ruminant nutrition. San Diego: Academic Press, 1990. 483p.

MOOJEN, E.L. Dinâmica e potencial produtivo de uma pastagem nativa do Rio Grande do Sul submetida a pressões de pastejo, épocas de diferimento e níveis de adubação. Porto Alegre: Universidade Federal do Rio Grande do Sul, 1991. 172p. Tese (Doutorado em Forragicultura) Universidade Federal do Rio Grande do Sul, 1991.

MORAES, A.A.S.; LOBATO, J.F.P. Efeito de duas épocas de desmame no desempenho reprodutivo de vacas de corte. Revista Brasileira de Zootecnia, v.22, n.6, p.1003-1011, 1993.

MORENO, J.A. Clima do Rio Grande do Sul. Porto Alegre: Secretaria da Agricultura, 1961. 41p.

MUEHLMANN, L.D.; ROCHA, M.G.; RESTLE, J. Efeito do uso exclusivo de pastagens no desenvolvimento de bezerras de corte desmamdas precocemente. Revista Brasileira de Zootecnia, v.26, n.2, p.411-415, 1997.
NATIONAL RESEARCH COUNCIL - NRC. Nutrient requirement of beef cattle. 6 .ed. Washington, D.C.: National Academy Press, 1984. 90p.

PATTERSON, D.J.; PERRY, R.C.; KIRACOFE, G.H. et al. Management considerations in heifer development and puberty. Journal of Animal Science, v.70, n.12, p.40184035, 1992.

POPPI, D.P.; McLENNAN, S.R. Protein and energy utilization by ruminants at pasture. Journal of Animal Science, v.73, n.1, p.278-290, 1995.

POPPI, D.P.; HUGHES, T.P.; L'HUILLIER, P.J. Intake of pasture by grazing ruminants. In: NICOL, A.M. (Ed.) Feeding livestockon pasture. Hamilton: New Zealand Society of Animal Production, 1987. p.55-63.

PÖTTER, L.; LOBATO, J.F.P.; MIELITZ NETTO, C.G. Análises econômicas de modelos de produção com novilhas de corte primíparas aos dois, três e quatro anos de idade. Revista Brasileira de Zootecnia, v.29, n.3, p.861-870, 2000.

REARTE, D.H.; PIERONI, G.A. Supplementation of temperate pastures. In: INTERNATIONAL GRASSLAND CONGRESS, 19., 2001, São Pedro. Proceedings... São Pedro: Sociedade Brasileira de Zootecnia, 2001, p.679-689.

RESTLE, J.; SENNA, D.B.; POLLI, V.A. Desenvolvimento até os 24 meses de novilhas de diferentes grupos genéticos submetidas a duas idades de desmame. In: REUNIÃO ANUAL DA SOCIEDADE BRASILEIRA DE ZOOTECNIA, 1992, Lavras. Anais... Lavras: Sociedade Brasileira de Zootecnia, 1992, p.191.

ROCHA, M.G.; LOBATO, J.F.P. Sistemas de alimentação pósdesmama de novilhas de corte para acasalamento com 14/15 meses de idade. Revista Brasileira de Zootecnia, v.31, n.4, p.1814-1822, 2002.

RYAN, W.J. Compensatory growth in cattle and sheep. Nutrition Abstracts and Reviews (Series B), v.60, n.9, p.653-664, 1990.

TAMBARA, A.A.C.; OLIVO, C.J.; PIRES, M.B.G. et al. Avaliação in vivo da digestibilidade da casca do grão de soja moída com ovinos. Revista Ciência Rural, v.25, n.2, p.283-287, 1995.

TILLEY, J.M.A.; TERRY, R.A.A. Two stage technique for the "in vitro" digestion of forage crops. Journal of British Grassland Society, v.18, n.2, p.104-111, 1963. 